\section{The Need for Continuous Systems Thinking in Public Health in Canada}

\section{Dear Editor:}

In a letter published in the November/December 2010 issue of the CJPH (Vol. 101, No. 6, pg. 499), a group of public health leaders in Canada called for the Canadian Public Health Association (CPHA) to establish an ongoing open forum for systematic reflection on public health system(s) elements in Canada as part of its annual conference. This call recognized that health system(s) reform in the country requires systems thinking in public health. CPHA recognized this need and offered us the opportunity to debate these issues at the 2011 conference.

The 2011 panel reflected on recent changes in Canada's public health landscape. The federal, provincial and territorial (F/P/T) Ministers of Health and Healthy Living endorsement of a new declaration on disease prevention and health promotion emphasizes the importance of multisectoral partnerships. The Pan-Canadian Public Health Network has been restructured to maximize its efficiency and effectiveness in addressing the most important public health questions. At the provincial level, Québec continues to have health and social services administered by the same ministry, which facilitates systematic integration of public health services across jurisdictions, from local to regional to provincial and across interdependent sectors. In British Columbia, public health, previously under a separate ministry, has been merged into Ministry of Health and Safety. In Ontario, the new public health agency (now called Public Health Ontario) developed a new strategic plan, while the Ministry of Health Promotion and Sport is now folded back into the Ministry of Health and Long-Term Care and the 14 Local Health Integration Networks (LHINs) continue to manage the care system. Alberta has moved away from regional offices to one board and is now back to two zones. In Nova Scotia, a new Health and Welfare Department has been created. In Newfoundland and Labrador, it is the Child and Welfare Service that covers public health. While many of these changes in the landscape are positive, the public health system(s) remains a multilevel and multiplayer puzzle. Recognizing the need for systems thinking and continuous optimization of governance mechanisms to ensure that public health system(s) are coherent, several important points are highlighted below.

First, from the example of Québec, where health and social services are integrated into the same ministry, a structure exists that provides both horizontal and vertical integration (provincial, regional and local). Moreover, using the legislative lever of Section 54 of the Public Health Act (1998), additional intersectoral action is achieved by requiring other ministries to undertake health impact assessments (HIA) for any important legislative or policy interventions that have a potential impact on health. This "natural experiment" offers opportunities to generate comparative evidence for system integration approaches and help improve intersectoral decision-making.
Second, a systems approach involves incentives, connectors and relationships. If we look at the obesity epidemic as a systems challenge, it is clear that we have the necessary components of the system. We have made good investments in knowledge generation and exchange, and we have innovation happening across the country at local, provincial/territorial and national levels. But we are missing connections, motivators and good comparative data to get the system to function as a whole. The health sector is only one player in the obesity solution. Our connections to employment, finance, transportation, and the agricultural sectors, for example, could be enhanced. An overly health-centric approach makes genuine links with these other sectors more challenging.

Third, while we have been doing a better job in this area recently, we can do more to make sure that we do not lose sight of the system when developing the object of research. In addition, we need to fundamentally re-imagine the questions that we are asking and reshape the drivers that orient researchers in particular directions. The predominantly short-term nature of research funding cycles, the challenges of reviewing interdisciplinary research, and a preference for research projects that more quickly yield findings and publications all impede research approaches that are more consistent with systems thinking in public health. Universities, researchers and funding agencies should be encouraged to get out of their "safety zones" and take on more complex and long-term system-related issues.

It will require the steadfast and continual efforts of decisionmakers, practitioners and researchers working across all sectors, to fully embrace the challenges and opportunities of systems thinking in public health.

Garry Aslanyan, Policy Manager, TDR, World Health Organization (WHO), Geneva, Switzerland

Lucie Granger, Directrice générale, Association pour la santé publique du Québec, Montréal, QC

Nancy Edwards, Scientific Director, CIHR's Institute of Population and Public Health (CIHR-IPPH), Ottawa, Ontario; Professor, University of Ottawa

Kim Elmslie, Director General, Centre for Chronic Disease Prevention and Control, Public Health Agency of Canada, Ottawa, Ontario

Pamela Fralick, Co-Chair, Canadian Coalition for Public Health in the 21 $1^{\text {st }}$ Century (CCPH21); President and CEO, Canadian Healthcare Association, Ottawa, Ontario

Alain Poirier, Directeur national de santé publique et Sous-ministre adjoint à la Direction générale de la santé publique, Ministère de la Santé et des Services sociaux, Ville de Québec, Québec 